\title{
Comparison and Assessment of Two Load Flow Methods for Optimum Under Voltage load Shedding in Distribution Power System
}

\author{
Waleed Khalid Shakir Al-Jubori ${ }^{1}$, Ali Nasser Hussain ${ }^{2}$ \\ \{waled_k@atu.edu.iq/wjubori@gmail.com¹, alinasser1974@yahoo.com² \\ Technical College of Al-Mussaib, Al-Furat Al-Awsat Technical University, Babil, Iraq ${ }^{1}$ \\ Electrical Engineering Technical College, Middle Technical University, Baghdad, Iraq ${ }^{2}$
}

\begin{abstract}
Under voltage load shedding is considered to avoid voltage collapse. Usually, the loads are modelled as constant power types, while different load models are used in load flow studies. A study of optimal load shedding is presented in this research, along with a comparison and evaluation of two load flow methods taking into account various load models. The algorithm is used optimised Dolphin method to oachieve the voltage values of buses while also reducing losses. Under the health and fault cases of the system, a comprehensive comparison and assessment of the optimization performances for four different load shedding models constant power, constant current, constant impedance, and composite ZIP models were performed to determine which model provides the most improvement in the voltage profile and loss reduction using the MATLAB programme.
\end{abstract}

Keywords: Voltage stability, Under voltage load shedding, Backward-Forward load flow, Dolphin optimization algorithm.

\section{Introduction}

The electrical power system is often operated with its stability boundaries. The in equipoise of active and reactive power can lead to simultaneous voltage instability and if the imbalance between the reactive and active power increased the system will be collapse eventually [1]. The under-voltage scheme is designed as it represents the ultimate line of protection against voltage instabilities based on the determination of distribution for load shedding using the voltage magnitude datum. A methodology of Under Voltage Load Shedding (UVLS) is proposed and solved utilizing Particle Swarm Optimization (PSO) [2].

An efficient load shedding using a genetic algorithm to improve the voltage stability is given in reference [3]. The taking apart (outage) of a considerable generating unit or failure of a highly loaded transmission line can cause the system (collapse). Under such a situation, load shedding is undertaken to avoid the voltage failure situation after exhausting all other countermeasures. An advanced method of UVLS is submitted which deals in the emergency condition without manipulated the constraints [4]. It uses the P-V curves and a UVLS logic relay design in the MAT LAB Simulink.

The UVLS scheme based on voltage stability index (VSI) for distribution network is proposed in [5]. A distribution network energized by two DGs has been implemented in PSCAD software to test the UVLS scheme. In [6], a UVLS scheme is proposed. The optimal pattern of load shedding subject to technical constraints is determined using the proposed scheme. The 
predefined voltage stability margin is determined using the minimum load shedding pattern results for the proposed algorithm while meeting the operational constraints.

A new technique of load shedding by using hybrid optimization is proposed in reference [7]. In addition to weak buses identification by its capability of identifying critical areas in a large power system using the Quick Voltage Stability Index (QVSI), determining the voltage failure point, the highest allowable load, and an interlinked scheme of the most important line. A modern adaptive and centralized of (UVLS) to reduce the short-term voltage instability while analysing the UVLS core challenges is produced in reference [8]. The load shedding is estimated and dependent on the local measurements needed for the proposed method. The (UVLS) scheme using Ant Lion Optimizer (ALO) is presented in reference [9]. The position of the load bus to be shed is selected based on the (VSI).

\section{Optimal Load Shedding for Distribution System}

UVLS assesses itself as to be such a technique for voltage instability and collapse prohibition as it is very frugal and simple to implement [10]. The voltage on the most sensitive buses decreases when the system heavily loads which results in a shortage of reactive power backup and also this can happen due to poorly organized reactive power service. The UVLS is defined as a correction factor after some control actions failed to react with the critical operating mode which results in the power flow can be unresolved [11]. Because of economic reasons, the use of optimal load shedding can decrease financial losses and enhance the voltage profile. The optimal load shedding with a suitable optimization algorithm provides the following advantages:

1. The accurate and optimum calculation for load shedding.

2. Reliable and powerful performance.

3. The ability to implement in modern and complex systems.

\section{Methodology of Load Flow}

Traditional load flow strategies example Newton Raphson Method (NRM) are insufficient and can differ due to radial and high ratio of $\mathrm{R} / \mathrm{X}$ ratio electrical distribution systems [12]. As a result, other methodologies, such as the Direct Backward - Forward Sweep Method, are more advanced (DBFSM). Under-voltage load shedding is used, and a comparison of the methodologies is used to demonstrate the effectiveness of DBFSM load flow. [13] describes the main phases of the load (power) flow mechanism.

\section{Types and Load Modeling}

The findings of study into stability and load flow have highlighted choices that are necessary to improve the overall effectiveness of the power system. As a result, all component models must be combined into a single mathematical model to describe the overall power system. The load simulation can affect the outcome of this study. The static and dynamic load models are the two types of load representation models, and this study focuses on the static load 
model. Two variants of the static load model: exponential and polynomial models; which are most generally used for load flow solutions. [14].

\subsection{Exponential Load Model}

Active and reactive powers are derived from this model as a function of the bus bar given (voltage \& frequency). An exponential voltage (V) of static load is given by:

$P_{d}=P_{0}\left(\mathrm{~V} / V_{0}\right)^{n p}$

$Q_{d}=Q_{0}\left(\mathrm{~V} / V_{0}\right)^{n q}$

Where: $\left(P_{d}, Q_{d}\right)$ are represent the desired of active and reactive power, $\left(P_{0}, Q_{0}\right)$ are represent the consumption of active and reactive load power, $\left(n_{p}, n_{q}\right)$ indicatethe exponent of active and reactive power and $\left(V, V_{0}\right)$ are supply and rated voltage. The magnitudes of $n p$ and $n q$ are stated in [15].

\subsection{Model of Polynomial Load}

In electrical power systems, many types of loads are employed, and each node has a specific fraction of these loads, which fluctuate over time. ZIP model is the most widely used model that incorporated with (P-model), (I-model), and (Z-model). This model is evident as [16]:

$P=\alpha P_{0} V^{2}+\beta P_{0} V+\gamma P_{0}$

$Q=\alpha Q_{0} V^{2}+\beta Q_{0} V+\gamma Q_{0}$

$\alpha+\beta+\gamma=1$

The percentage contribution of constant $(\mathrm{Z})$, constant $(\mathrm{I})$, and constant $(P)$ in each node is expressed by $\alpha, \beta$, and $\gamma$. Active power and reactive power are only studied based on the alterations in voltage, but the disparity in power dependent on alterations is not investigated. In this study, $\alpha=0.6, \beta=0.2$, and $\gamma=0.2$ are selected to provide the best outcomes for reducing the system losses and improving the voltage level.

\section{Application of Dolphin for Load Shedding Problem}

Initially, Dolphins explore all areas in the seeking area around it to expose the prey. The Dolphin narrows the search process at the moment the Dolphin hits the target and increases the swill clicks to focus on the position of the prey. This technique imitates the control of pursuing the echolocation of the Dolphin about the mileage from the bait [17]. The seeking space should be arranged based on the organizing form tabulated in [18]. The detailed steps of DOA are explained in the reference [19]. The optimal DOA parameters are recorded in Table 1.

Table 1. Optimum DOA parameters

\begin{tabular}{lc}
\hline Parameter Type & Rate (Value) \\
\hline Population & 30
\end{tabular}




$\begin{array}{lr}\text { Probability } & 0.1 \\ \text { No. of Iteration }=\operatorname{Max}(\text { N. R) } & 30 \\ \text { No. of Iteration }=\operatorname{Max}(B-F) & 90\end{array}$

\section{Objective Functions}

Minimize Ploss within multi-objective functions is profitable including the boost of voltage values for system buses (voltages profile).

\subsection{Reduction of $\left(P_{\text {loss }}\right)$ (objective function. 1$)$}

(ob. fun. 1) $=P_{\text {loss }}$

$P_{\text {loss }}=\sum_{l=1}^{N_{b r}} P_{\text {lossl }} \mathrm{kW}$

$P_{\text {lossl }}=I_{l}^{2} * R_{l} \mathrm{~kW}$

Where: $P_{\text {loss }}:$ is the overall losses, $N_{b r}$ : is the branches, $R_{l}:$ is the resistance of branch $l, I_{l}:$ is the flowing current in the branch $l$.

\subsection{Voltage Profile Enhancement (ob. fun. 2)}

Appropriate voltages range should be applied:

(ob.fun. 2) $=V_{C} * R e_{v}+C_{C} * R e_{i}$

Where Vc denotes the bus voltage limitations, Cc denotes the branch current limits, and Rev: Bus voltage retaliation variable. Branch currents' vengeance element, according to Rei. If the branch current fails to reach the thermal limit, this parameter is set to zero.

After implementing the load shedding process, optimizing problem savings depends on the cost of base power losses, taking into account the cost coefficient equal to $(0.06 \$ / \mathrm{KWH}$ [20].To brew the compound final objective function (ob.fun.f), the two objective functions of lowering $\left(P_{\text {loss }}\right)(o b . f u n .1)$ and improving the voltage profile (ob.fun. 2$)$ are combined

ob.fun. $f=$ ob.fun. $1+$ ob.fun. 2

\section{General Constraints}

\subsection{The Technical Constraints}

The constraints have stated the limits required into of the following groups:

i. Limitations(constraints) of bus voltage 
The voltage value for each of the system buses can be stated as:

$\left|V_{\text {jmin. }}\right| \leq\left|V_{j}\right| \leq\left|V_{\text {jmax. }}\right| \quad j \in N_{\text {bus }}$,

Where: $\left(N_{b u s}\right)$ is the number of buses on the network.

The voltage buses are $(0.95-1.05)$ p.u[21].

ii. Limitations (Constraints) of branch current

On the one hand, the branch current must not exceed a predetermined maximum amount while still assuring load power transmission continuity [22].

$\left|I_{l}\right| \leq\left|I_{\text {lmax. }}\right| \quad l \in N_{b r}$

Where: $\left(N_{b r}\right)$ is the number of branches of the system.

\subsection{Operational Limitations (Constraints)}

These kinds of constraints are known as boundaries of equality and are divided into two sorts:

i. Radial (constraints) for whole system loads

The radial system configuration condition is verified by looking at the determinant of the [A], which has rows $=$ branches and columns $=$ number of buses, as shown below [23]:

$[A]=\left\{\begin{array}{l}1 \text { If the branch } i \text { is out from bus } j \\ -1 \text { if the branch } i \text { is inside into bus } j \\ 0 \text { if the branch } i \text { is not linked to bus } j\end{array}\right.$

ii. Constraint) of balancing real power

$P_{\text {Sup }}=P_{\text {Dem }}+P_{\text {loss }}$

Where $\left(P_{s u b}\right)$ is the sum of real power that supplied to the power system, $\left(P_{D e m}\right)$ is the overall demand of real power from the load.

\section{Simulated Results}

The DOA optimization procedure was designed and implemented in a computer programme using the MATLAB program. It is applied to reduce the searching space for the IEEE Radial Distribution System (RDS), which is used to choose shaded bus locations and shading amounts. Figure 1 depicts the RDS single-line diagram case study. 


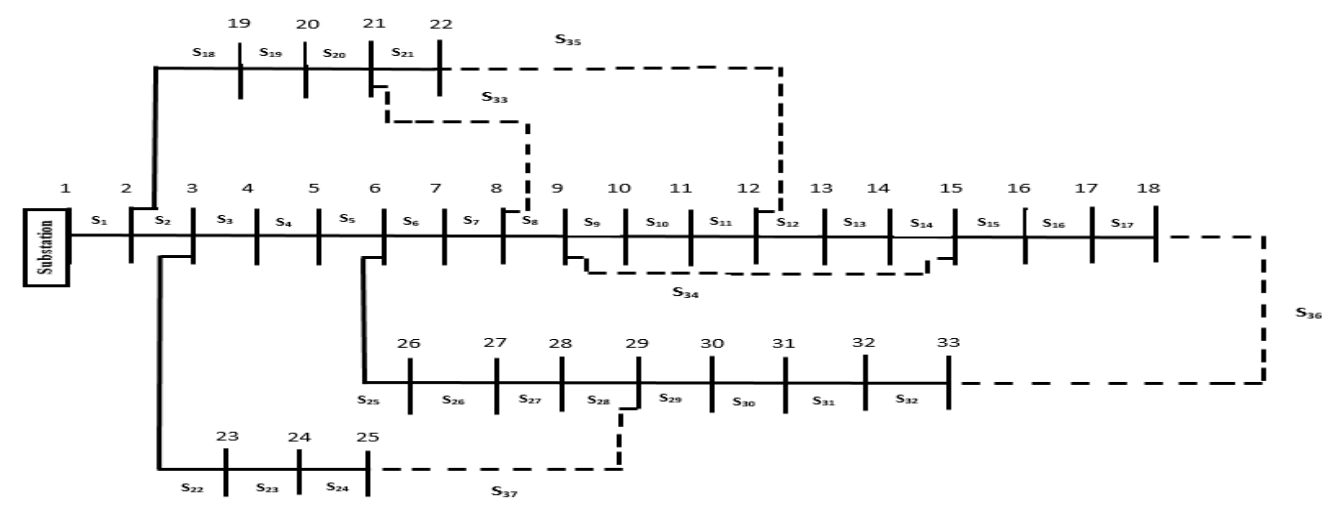

Fig 1. The RDS single line diagram of standard IEEE- 33 bus.

It includes (1 primary, 3 lateral) feeders, 37 branches, 5 opened and 32 closed switches. The system data with tie switches are given in [24]. The steps for UVLS are carried out by the selection of 3- buses. The network is studied for healthy and faulty cases when one of the lines is isolated and the network reconnected using an alternative tie-line.

\subsection{Standard IEEE 33 bus for healthy case}

Table 2 shows the results and comparisons between several load models with UVLS towards the optimal path of 3 buses using DOA and a healthy network for the optimal option of three buses using DOA and a healthy network.

Table 2. Results without and with UVLS by using (N.R) method at the healthy case.

\begin{tabular}{|c|c|c|c|c|c|c|c|c|}
\hline \multirow{2}{*}{ Item } & \multicolumn{2}{|c|}{$\begin{array}{c}\text { Normal (Const.P) } \\
\text { model }\end{array}$} & \multicolumn{2}{|c|}{ Const. (I) model } & \multicolumn{2}{|c|}{ Const. (Z) model } & \multicolumn{2}{|c|}{ ZIP model } \\
\hline & W.O & W. & W.O & W. & W.O & W. & W.O & W. \\
\hline P. loss $(\mathrm{kW})$ & 202.23 & 158.04 & 175.99 & 137.09 & 162.92 & 125.97 & 157.55 & 120.2 \\
\hline Q.loss (kVAr) & 134.47 & 95.11 & 116.95 & 85.57 & 108.24 & 80.56 & 104.65 & 78.04 \\
\hline Location & - & $6,28,13$ & - & $6,8,13$ & - & $6,8,13$ & - & $6,28,13$ \\
\hline $\begin{array}{l}\text { Proportional } \\
\text { Shed Amount }\end{array}$ & - & $\begin{array}{c}0.191,0.24 \\
0.19\end{array}$ & - & $\begin{array}{c}0.19,0.23, \\
0.189\end{array}$ & - & $\begin{array}{c}0.189,0.23, \\
0.188\end{array}$ & - & $\begin{array}{c}0.116,0.16 \\
0.115\end{array}$ \\
\hline $\begin{array}{l}\text { Shed } \\
\text { Percentage }\end{array}$ & - & $20.7 \%$ & - & $20.67 \%$ & - & $20.59 \%$ & - & $13.2 \%$ \\
\hline $\begin{array}{l}\text { Losses } \\
\text { Reduction\% }\end{array}$ & - & $21.85 \%$ & - & $22.1 \%$ & - & $22.67 \%$ & - & $23.65 \%$ \\
\hline Vol.min. & 0.911 & 0.95 & 0.918 & 0.95 & 0.9226 & 0.95 & 0.924 & 0.95 \\
\hline Vol. max. & 1.00 & 1.00 & 1.00 & 1.00 & 1.00 & 1.00 & 1.00 & 1.00 \\
\hline
\end{tabular}

(W.O. = Without, $\mathrm{W}=$ With) 
When comparing various UVLS models using the N.R approach, the results reveal that the best model is the ZIP type. The implementation of a backward-forward technique based on the optimal selection of buses by DOA, as shown in Table 3, improves these findings.

Table 3. Results without and with UVLS by using (B-F) method at the healthy case.

\begin{tabular}{|c|c|c|c|c|c|c|c|c|}
\hline \multirow{2}{*}{ Item } & \multicolumn{2}{|c|}{$\begin{array}{c}\text { Normal (Const.P) } \\
\text { model }\end{array}$} & \multicolumn{2}{|c|}{ Const. (I) model } & \multicolumn{2}{|c|}{ Const. (Z) model } & \multicolumn{2}{|c|}{ ZIP model } \\
\hline & W.O & W. & W.O & W. & W.O & W. & W.O & W. \\
\hline P.loss (kW) & 202.677 & 158.18 & 176.627 & 137.55 & 156.87 & 120.61 & 151.14 & 113.92 \\
\hline Q.loss kVAr) & 577.99 & 91.85 & 117.51 & 83.87 & 104.17 & 77.16 & 100.47 & 74.72 \\
\hline Location & - & $6,28,13$ & - & $6,28,13$ & - & $6,28,13$ & - & $6,28,13$ \\
\hline $\begin{array}{l}\text { Proportional } \\
\text { Shed Amount }\end{array}$ & - & $\begin{array}{l}0.214,0.167, \\
0.185\end{array}$ & - & $\begin{array}{c}0.201,0.154 \\
0.172\end{array}$ & - & $\begin{array}{c}0.177,0.13 \\
0.148\end{array}$ & - & $\begin{array}{c}0.15,0.103, \\
0.121\end{array}$ \\
\hline Shed.Percent. & - & $18.87 \%$ & - & $17.58 \%$ & - & $15.18 \%$ & - & $12.46 \%$ \\
\hline $\begin{array}{l}\text { Losses } \\
\text { Reduction\% }\end{array}$ & - & $21.95 \%$ & - & $22.12 \%$ & - & $23.11 \%$ & - & $24.62 \%$ \\
\hline Vol.min. & 0.913 & 0.95 & 0.919 & 0.95 & 0.924 & 0.95 & 0.9256 & 0.95 \\
\hline Vol..max. & 1.00 & 1.00 & 1.00 & 1.00 & 1.00 & 1.00 & 1.00 & 1.00 \\
\hline
\end{tabular}

Table 3 demonstrates how the ZIP model with the B-F approach improved the voltage values of system buses while lowering the values of real losses. In addition, each bus's shed quantity is lowered. With two power flow methods, Figs 2-9 illustrate the voltage values of system buses (voltage profile) and the values of power losses for each system branch in the healthy condition.

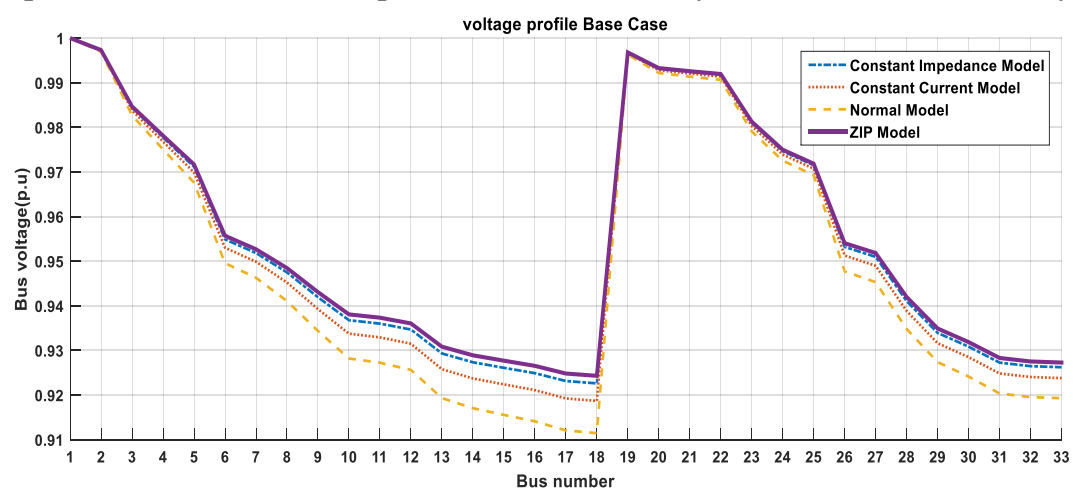

Fig 2. Voltage profile without UVLS at healthy case by using (N.R.). 


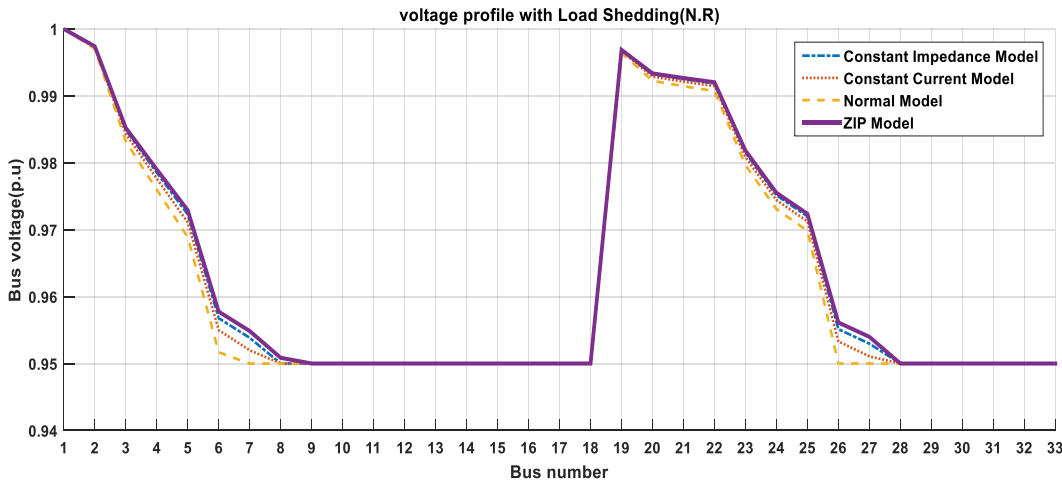

Fig 3. Voltage with UVLS at healthy case by using (N.R.).

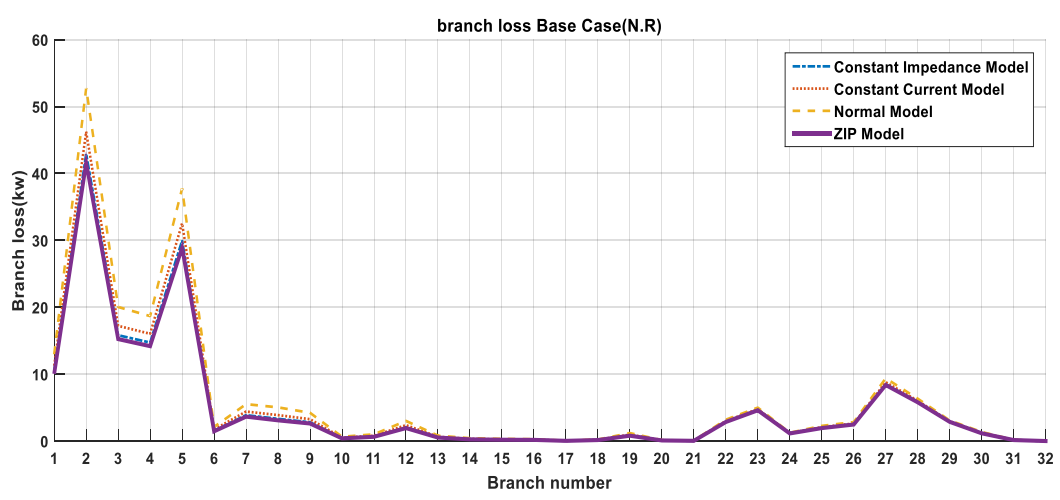

Fig. 4. Branch loss without UVLS at healthy case by using (N.R.).

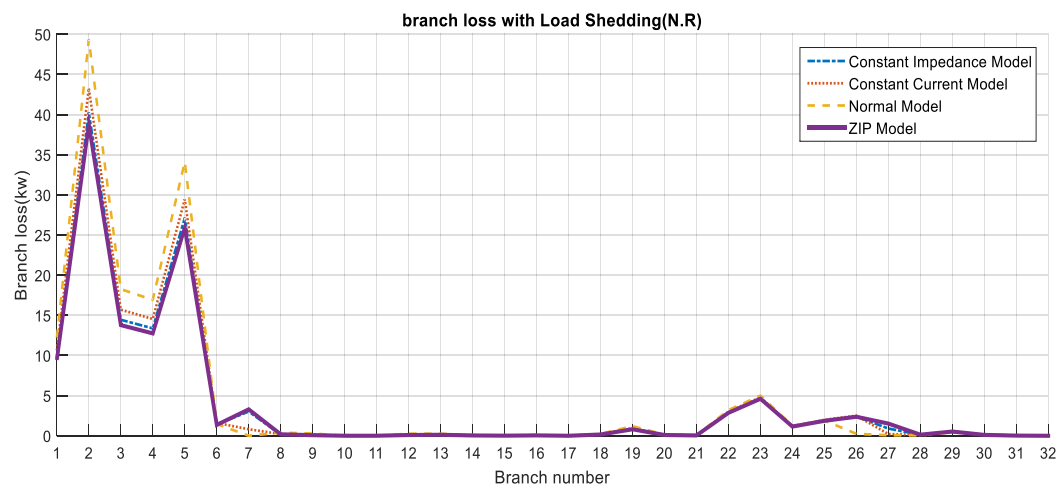

Fig. 5. Branch with UVLS at healthy case by using (N.R.). 


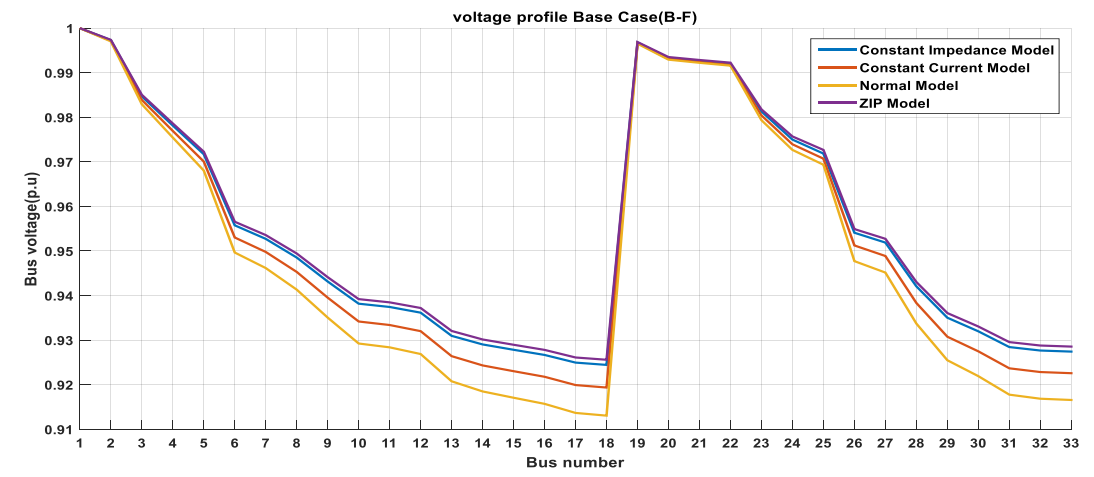

Fig. 6. Voltage profile of standard 33 bus network without UVLS at healthy case by using (B-F).

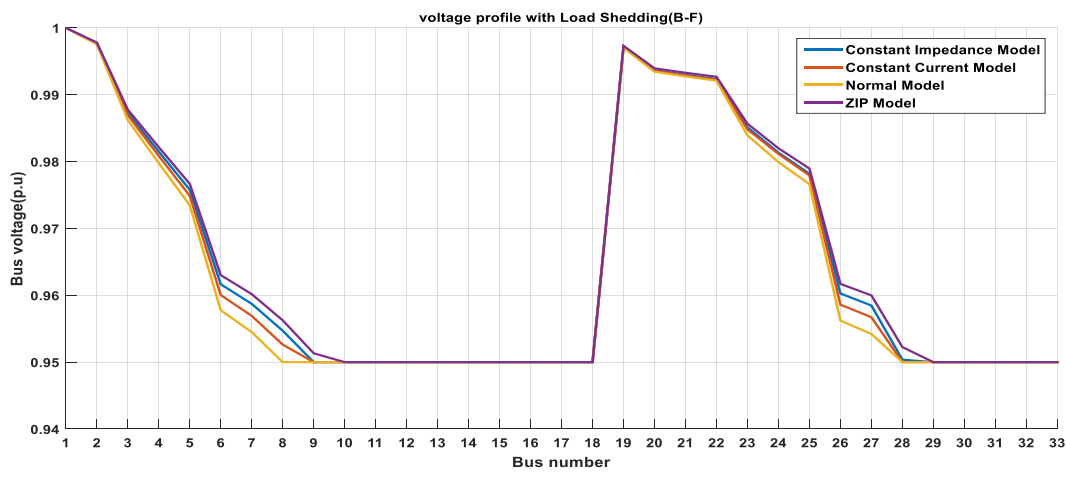

Fig.7. Voltage profile with UVLS at healthy case by using (B-F).

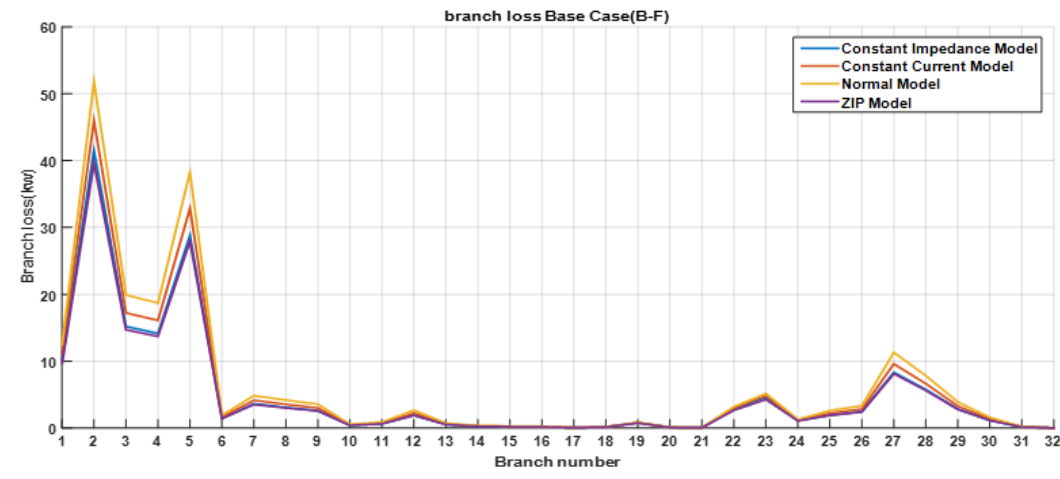

Fig. 8. Branch loss without UVLS at healthy case by using (B-F). 


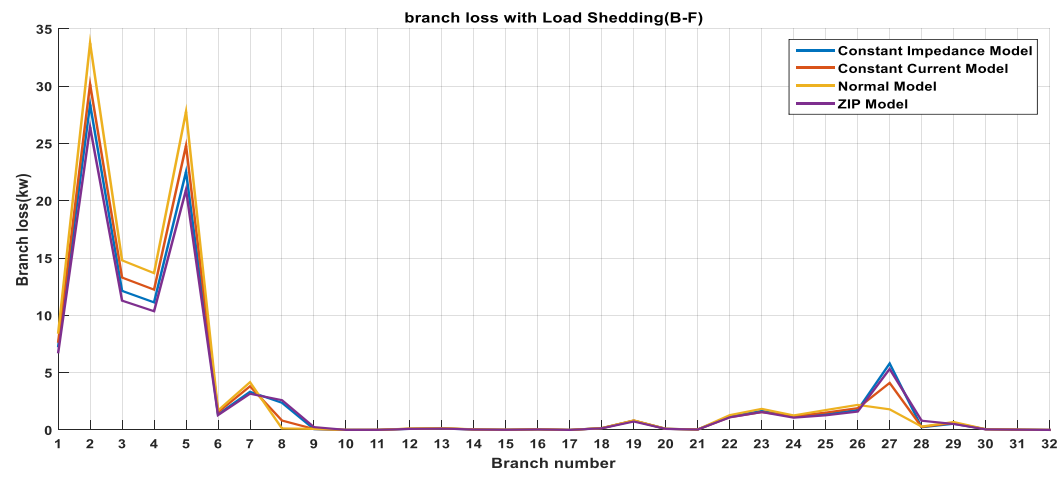

Fig. 9. Branch loss with UVLS at healthy case by using (B-F).

\subsection{Standard IEEE 33 Bus for Faulty Case}

The acquired results and rapprochement for the optimal option of three buses utilising DOA and defective network using various load models based on the power flow of Newton-Raphson technique without and with UVLS. The network is rejoined using tie-line (25-29), where there are five tie switches in the network, after line (28-29) is isolated.

The results reveal that the ZIP model type outperforms all other models when it comes to UVLS utilising the N.R approach. The B-F technique, which is based on DOA's optimal selection of shaded buses, improves these findings (see Table 4).

The results show that the ZIP model type is the best load model among the other models for UVLS utilising the N.R approach.

Table 4. Results of standard 33 bus without and with UVLS by using (N.R) method at the faulty case.

\begin{tabular}{|c|c|c|c|c|c|c|c|c|}
\hline \multirow{2}{*}{ Item } & \multicolumn{2}{|c|}{$\begin{array}{c}\text { Normal (Const. P) } \\
\text { model }\end{array}$} & \multicolumn{2}{|c|}{ Const. (I) model } & \multicolumn{2}{|c|}{ Const. (Z) model } & \multicolumn{2}{|c|}{ ZIP model } \\
\hline & W.O & W. & W.O & W. & W.O & W. & W.O & W. \\
\hline P.loss (kW) & 236.02 & 168.46 & 207.13 & 146.51 & 192.66 & 134.21 & 186.69 & 127.84 \\
\hline Q. loss kVAr) & 159.46 & 92.44 & 140.02 & 90.82 & 130.28 & 86.07 & 126.27 & 84.89 \\
\hline Location & - & $6,28,13$ & - & $6,28,13$ & - & $6,28,13$ & - & $6,28,13$ \\
\hline $\begin{array}{l}\text { Proportional } \\
\text { Shed Amount }\end{array}$ & - & $\begin{array}{c}0.26,0.15 \\
0.148\end{array}$ & - & $\begin{array}{c}0.19,0.17 \\
0.17\end{array}$ & - & $\begin{array}{c}0.16,0.15 \\
0.145\end{array}$ & - & $\begin{array}{c}0.13,0.12, \\
0.132\end{array}$ \\
\hline $\begin{array}{l}\text { Shed } \\
\text { Percentage }\end{array}$ & - & $18.96 \%$ & & $17.85 \%$ & - & $15.18 \%$ & - & $12.76 \%$ \\
\hline $\begin{array}{l}\text { Losses } \\
\text { Reduction\% }\end{array}$ & - & $28.62 \%$ & & $29.26 \%$ & - & $30.33 \%$ & - & $31.52 \%$ \\
\hline Vol.min. & 0.906 & 0.95 & 0.911 & 0.95 & 0.913 & 0.95 & 0.915 & 0.95 \\
\hline Vol.max. & 1.00 & 1.00 & 1.00 & 1.00 & 1.00 & 1.00 & 1.00 & 1.00 \\
\hline
\end{tabular}


The B-F technique, which is based on DOA's optimal selection of shaded buses as shown in Table 5, improves these findings.

Table 5. Results of standard 33 bus without and with UVLS by using (B-F) at the faulty case.

\begin{tabular}{|c|c|c|c|c|c|c|c|c|}
\hline \multirow{2}{*}{ Item } & \multicolumn{2}{|c|}{$\begin{array}{c}\begin{array}{c}\text { Normal (Const. P) } \\
\text { model }\end{array} \\
\end{array}$} & \multicolumn{2}{|c|}{ Const. (I) model } & \multicolumn{2}{|c|}{ Const. (Z) model } & \multicolumn{2}{|c|}{ ZIP model } \\
\hline & W.O & W. & W.O & W. & W.O & W. & W.O & W. \\
\hline P. loss (kW) & 190.74 & 134.37 & 170.08 & 119.64 & 153.59 & 106.63 & 146.63 & 100.2 \\
\hline $\begin{array}{ll}\text { Q. } & \text { loss } \\
\text { (kVAr) }\end{array}$ & 125.2 & 81.74 & 111.57 & 75.54 & 100.69 & 69.48 & 96.16 & 65.37 \\
\hline Location & - & $24,25,6$ & - & $24,25,6$ & - & $24,25,6$ & - & $24,25,6$ \\
\hline $\begin{array}{l}\text { Proportional } \\
\text { Shed Amount }\end{array}$ & - & $\begin{array}{l}0.17,0.143 \\
\quad 0.222\end{array}$ & - & $\begin{array}{c}0.188,0.117 \\
0.222\end{array}$ & - & $\begin{array}{c}0.106,0.105 \\
0.222\end{array}$ & - & $\begin{array}{c}0.106,0.105, \\
0.153\end{array}$ \\
\hline $\begin{array}{l}\text { Shed } \\
\text { Percentage }\end{array}$ & - & $17.86 \%$ & - & $17.56 \%$ & - & $14.44 \%$ & - & $12.16 \%$ \\
\hline $\begin{array}{l}\text { Losses } \\
\text { Reduction\% }\end{array}$ & - & $29.55 \%$ & - & $29.65 \%$ & - & $30.59 \%$ & - & $31.6 \%$ \\
\hline Vol.min. & 0.928 & 0.95 & 0.932 & 0.95 & 0.936 & 0.95 & 0.937 & 0.95 \\
\hline Vol. max. & 1.00 & 1.00 & 1.00 & 1.00 & 1.00 & 1.00 & 1.00 & 1.00 \\
\hline
\end{tabular}

Additionally, utilising UVLS and the ZIP load model with the B-F approach, the findings obtained show an improvement in the voltage values of system buses (voltage profile) as well as loss reduction. In addition, each bus's shed quantity is lowered. Figures 10-17 depict the voltage values of system buses (voltage profile) and the values of power losses for each system branch in the defective situation using two power flow techniques, indicating that the ZIP model with B-F load flow method is superior to other models.

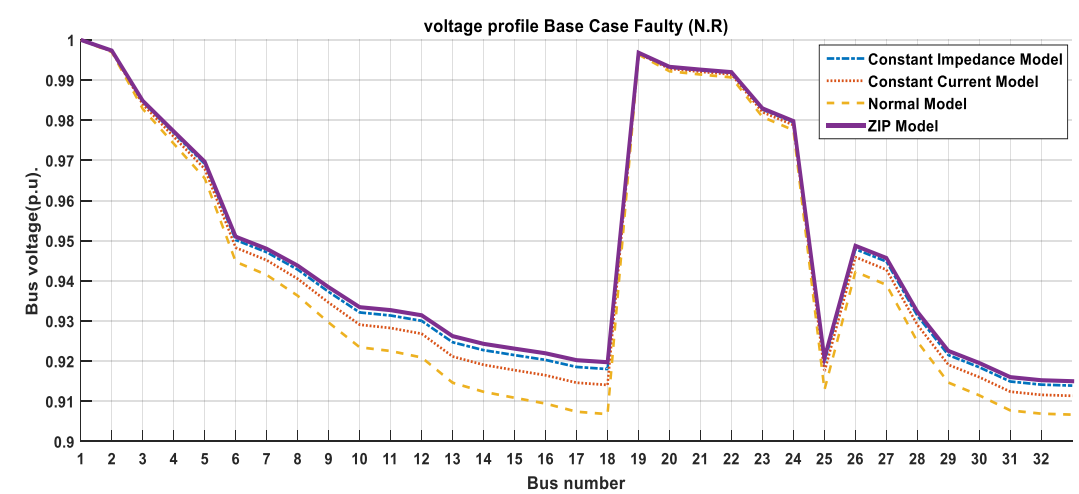

Fig. 10. Voltage profile without UVLS at faulty case by using (N.R.). 


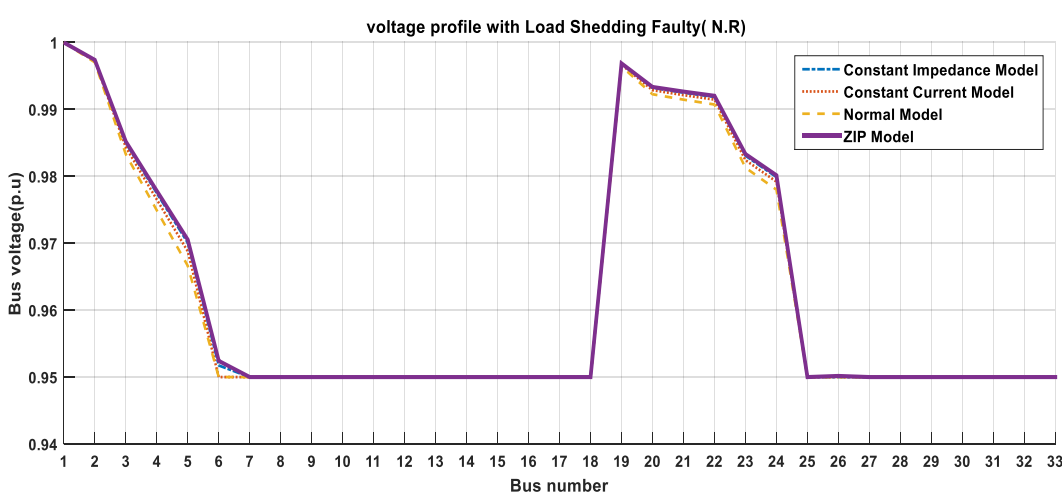

Fig. 11. Voltage profile with UVLS at faulty case by using (N.R.).

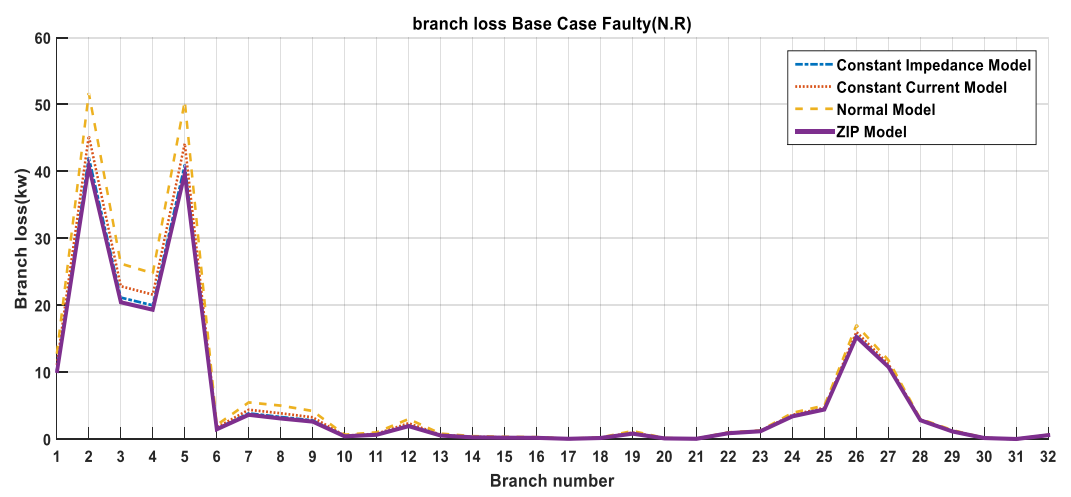

Fig. 12. Branch loss without UVLS at faulty case by using (N.R.).

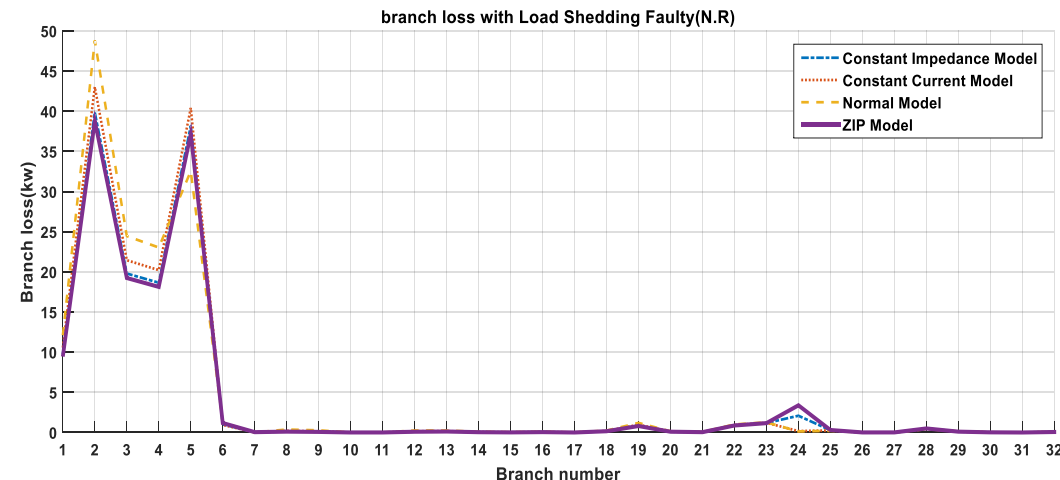

Fig.13. Branch loss of standard 33 bus network with UVLS at faulty case by using (N.R.). 


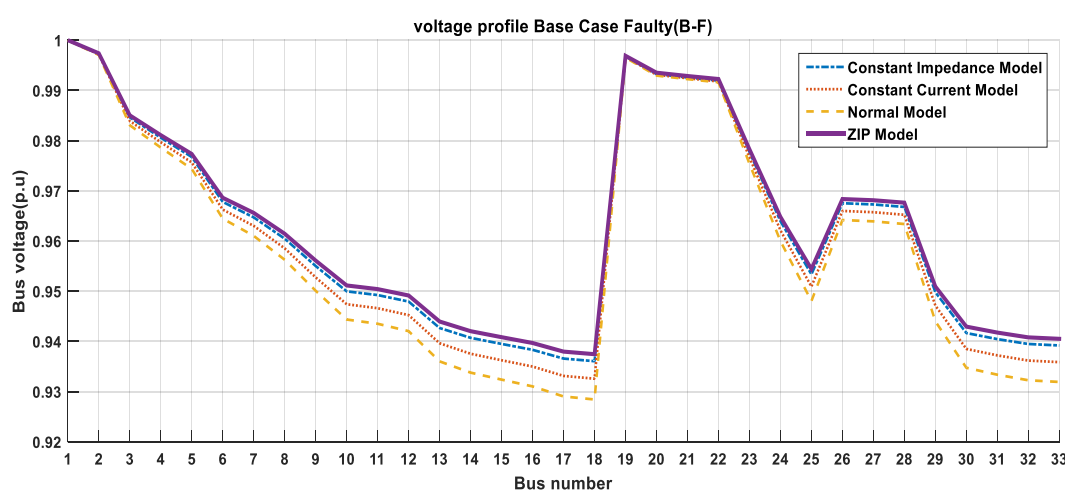

Fig.14. Voltage profile without UVLS at faulty case by using (B-F).

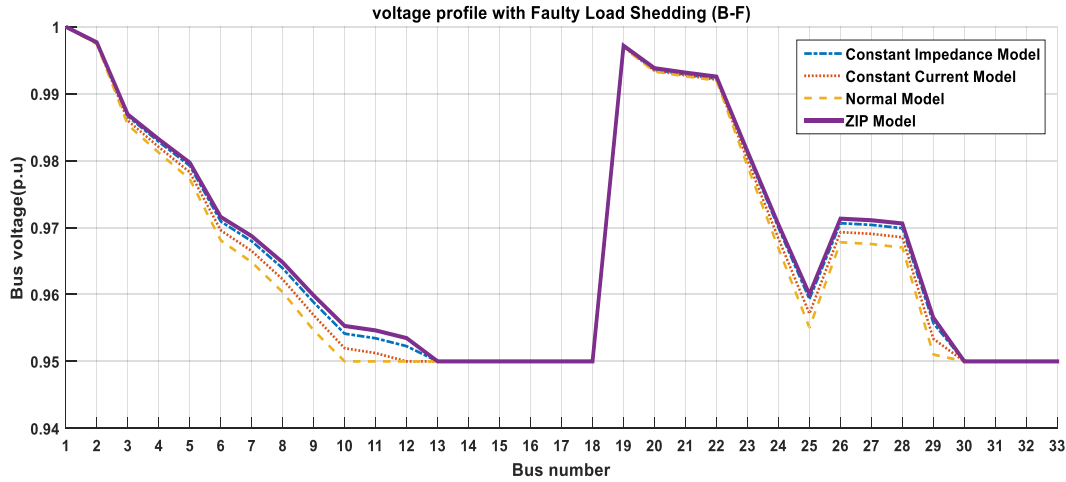

Fig. 15. Voltage profile with UVLS at faulty case by using (B-F).

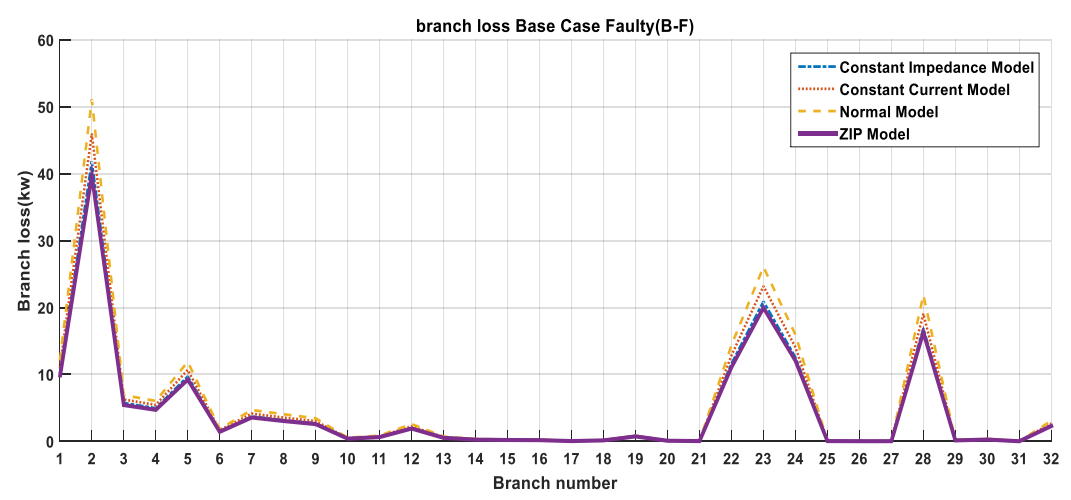

Fig. 16. Branch loss without UVLS at faulty case by using (B-F). 


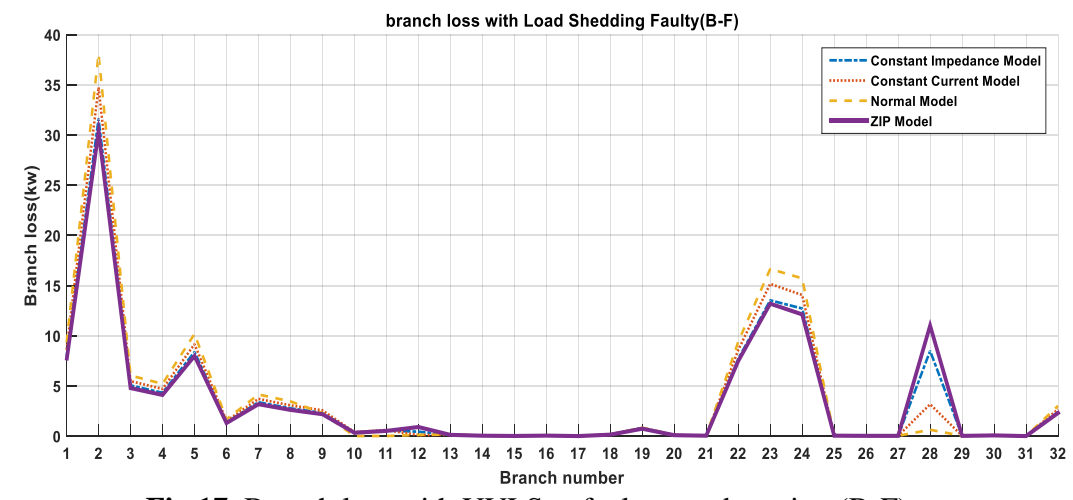

Fig.17. Branch loss with UVLS at faulty case by using (B-F).

\section{Conclusions}

To avoid voltage collapse, an under-voltage load shedding approach was adopted in this research. The DOA is used to determine the best placement and amount of load shedding for system buses in order to get the best voltage values (voltage profile) and losses reduction. In addition, based on the two-load flow methods Newton Raphson and Backward-Forward, comparison and assessment have been implemented among four different load models: constant I, constant Z, constant P, and ZIP models to identify the load model type that provided the most improvement in the voltage profile and loss reduction. The effectiveness of this method was validated through the 33-IEEE standard distribution power system under two cases health and fault. The outcomes show that the ZIP type is the superior model to provide the optimum resolution for load shedding strategy in comparison with other load models. Furthermore, the Backward-Forward load flow method outperforms the Newton Raphson method in terms of enhancing the voltage profile and increasing loss reduction.

\section{References}

[1] K. R. Gayathri and G. V. Maruteswar, "Frequency and Voltage Stability Assessment Applied to Load Shedding," International Journal of Engineering Trends and Technology, vol. 19, no. 2, pp. 106-115, 2015

[2] K. Lopez, S. Perez, and L. Rodrigues, "Optimal under voltage load shedding based on voltage stability index," Ingeieria E Investigation, vol. 36, No. 2, pp. 43-50, 2016.

[3] P. Chawla, and V. Kumar, "Optimal Load Shedding for Voltage Stability Enhancement by Genetic Algorithm," International Journal of Applied Engineering Research, vol. 7, no.11, pp. 2066-2070, 2012.

[4] R. M. Larik, M. W. Mustafa, S. H. Qazi, N. H. Mirijat, S. Shaikh, and A.R. Bhatti, "Under Voltage Load Shedding Scheme to Provide Voltage Stability," 4th International Conference on Energy, Environment and Sustainable Development 2016 (EESD 2016), pp1-7.

[5] N. A. Yusof, H. Mokhlis, M. Karimi, J. A. Laghari, H. A. Illias, and N. M. Sapari,"Under-Voltage Load Shedding Scheme Based on Voltage Stability Index for Distribution Network," Ingeniería e Investigación vol. 36, no. 2, pp. 43-50, 2016.

[6] I. K. Ashan, S. M. Taghi, M. Mortezaee, and T. Amaraee ,"A robust under voltage load shedding scheme against voltage instability," Turkish Journal of Electrical Engineering \& Computer Sciences, 
vol. 24, pp. 3309-3320, 2016.

[7] Raja M. Larik,M. W. Mustafa, and A.R. OkinoOtuoze,"A New Technique of Load Shedding to Stabilize Voltage Magnitude and Fast Voltage Stability Index by Using Hybrid Optimization," ARPN Journal of Engineering and Applied Sciences,vol. 13, no. 8, pp. 2734- 2745, 2018.

[8] J. Modarresi, E. Gholipour, and A. Khodabakashian," New Adaptive and Centralized Under-Voltage Load Shedding to Prevent Short -Term Voltage Instability," IET Generation, Transmission \& Distribution,vol.12, no. 11, pp. 2530-2538, 2018.

[9] Z. M. Yasin, H. Mohamad , I. N. Samon, N. A. Wahab, and N. A. Salim, "Optimal Undervoltage Load Shedding using Ant Lion Optimizer," Journal of Applied and Fundamental Sciences, vol. 10, no. 5S, 2018, pp. 426-443.

[10] M. Klaric, I. Kuzle, and S. Tesnjak, "Example of Undervoltage Load Shedding Implimentation," IEEE 2007, Windhoek, South Africa, pp. 1-6, 2007

[11] N. M. Sapari, H. Mokhlis, J. A. Laghari, A. H. A Bakar, M. R. M. Dahalan,"Application of Load Shedding Schemes for Distribution Network Connected with Distributed Generation: A review," Renewable and Sustainable Energy Reviews, vol. 82, no.1 , pp. 858-867, 2018.

[12] F. Teng, "Implementation of a Voltage Sweep Power Flow Method and Comparison with Other Power Flow Techniques," Semester Thesis, Swiss Federal Institute of Technology, Zurich, 2014.

[13] H. K. Verma, and P. Singh, "Optimal Reconfiguration of Distribution Network Using Modified Culture Algorithm," Journal of the Institution of Engineers , vol. 99, no. 6, pp. 613-622, 2018.

[14] N. A. Roustami and M. O. Sadegh,"The effect of load modelling on load flow results in distribution systems," American Journal of Electrical and Electronic Engineering, vol. 6, no.1, pp. 16-27, 2018.

[15] U. Eminoglu, and M. H. Hocaoglu," A new power flow method for radial distribution systems including voltage dependent load models," Electrical Power System Research, vol. 76, no. (1-3), pp. 106-114, 2005.

[16] S. Mok, S. Elangovan, C. Longiian, and M. Salama," A new approach of power flow analysis of balanced radial distribution systems," Electric Machines Power System,vol. 28, no.24, pp.325-340, 2000.

[17] K. Lenin, B. R. Reddy, and M. S. Kalavathi,"Dolphin echolocation algorithm for solving optimal reactive power dispatch problem," International Journal of Computer, vol. 12, no.1, pp. 1-15, 2014.

[18] A. Kaveh, N. Farhoudi,"A new optimization method: Dolphin Echolocation," Advances in Engineering Software, vol. 59, pp. 53-70, 2013.

[19] T. q. Wu, M. Yao, and J. H. Yang," Dolphin swarm algorithm", Frontiers of Information Technology \& Electronic Engineering, Frontiers of Information Technology \& Electronic Engineering, vol. 17, no. 8, pp. 717-729, 2016.

[20] A. A. El-Fergany, and A.Y. Abdelaziz, "Artificial Bee Colony Algorithm to Allocate Fixed and Switched Static Shunt Capacitors in Radial Distribution Networks," Electric Power Components and Systems, vol. 42, no. 5, pp. 427-438, 2014.

[21] M. R. Haghifam, and O.P. Malik, "Genetic Algorithm-based Approach for Fixed and Switchable Capacitors Placement in Distribution Systems with Uncertainty and Time Varying Loads," IET Generation Transmission \& Distribution, vol. 1, no. 2, pp. 244-252, 2007.

[22] R. S. Rao, S. V. L. Narasimham, M. R. Raju, and A. S. Rao, "Optimal Network Reconfiguration of Large-Scale Distribution System Using Harmony Search Algorithm,” IEEE Transactions on Power Systems, vol. 26, no. 3, pp. 1080 - 1088, 2011.

[23] M. Sedighizadeh, M. Ghalambor, and A. Rezazadeh, "Reconfiguration of Radial Distribution Systems with Fuzzy Multi-Objective Approach Using Modified Big Bang-Big Crunch Algorithm," Arabian Journal for Science and Engineering, vol. 39, no.8, pp. 6287-6296, 2014.

[24] Zhe Chen," A Study of Power Distribution System Reconfiguration based on Reliability Indices", A Thesis Presented to the Faculty of the Graduate School at the University of Missouri-Columbia, 2016. 